\title{
Impact of Using Tablet Computer and Smart Phone on Vision Performance In a Group of Visually Impaired Children
}

\author{
Akram Zarei ${ }^{1}$, Abbas Riazi ${ }^{* 2}$, Javad Heravian Shandiz ${ }^{3}$, Abdollah Farzaneh ${ }^{4}$ \\ 1. MSc, Department of Optometry, School of Paramedical Sciences, Mashhad University of Medical Sciences, Mashhad, \\ Iran \\ 2. PhD, Senior Lecturer, Department of Ophthalmology, School of Medicine, Baqiyatallah University of Medical Sci- \\ ences, Tehran, Iran. \\ 3. Professor, Department of Optometry, School of Paramedical Sciences, Mashhad University of Medical Sciences, Mash- \\ had, Iran \\ 4. PhD Candidate, Department of Optometry, Iran University of Medical Sciences, Tehran, Iran
}

\begin{tabular}{|c|}
\hline Article Info \\
\hline Received: 2018/08/13 \\
\hline Published Online: 2018/12/ \\
\hline DOI: 10.30699/fdisj.1.3.28 \\
\hline How to Cite This Article \\
\hline $\begin{array}{l}\text { Zarei A., Riazi A., Heravi- } \\
\text { an Shandiz J., Abdollah } \\
\text { F. Impact of Using Tablet } \\
\text { Computer and Smart Phone } \\
\text { on Vision PerformanceIn a } \\
\text { Group of Visually Impaired } \\
\text { Children. Function and Dis- } \\
\text { ability Journal. } 2018 \text { (Au- } \\
\text { tumn). Vol 1. No: 4. pages : } \\
\text { 28-35 }\end{array}$ \\
\hline
\end{tabular}

Use your device to scan and read the article online

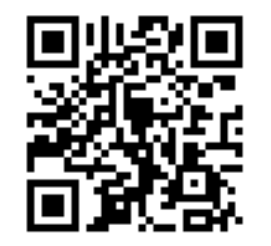

\section{ABSTRACT}

Background \& Objectives: To assess the effect of using tablets and smartphones on visual acuity and vision-related performance in a population of visually impaired children.

Methods: 24 children between the ages 4 to 13 years with visual acuity between 20/80 (0.6 Log Mar) to light perception participated in this study. The case group comprised children who scheduled to work with a tablet or smartphone for 2 hours a day for 6 months. The control group received nothing. Near and far vision as well as refraction were measured. Children of the two groups were asked to paint and the duration of painting was recorded. A questionnaire was designed to assess the quality of life the of children. All measurements were repeated 6 months later in both groups. There was no significant difference in vision between the two groups before using a tablet. Parents were also asked to explain any changes that occured in the behaviors of their children.

Results: Distant vision in the tablet group was significantly different from the control group $(P=0.04)$ which indicates improvement in visual acuity of the case group with about 0.20 Log Mar compared to the control group. There was 0.20 log Mar better vision in the tablet group in comparison with the control group $(P=0.04)$. Results from the questionnaire showed that in the tablet group, the score was about 14.04 units better than the control group. The time consumption for painting was the same in both groups after 6 months. There was no significant difference in near acuity and refractive errors. Interviews with parents showed improvement in the tablet group in the area of navigation, mobility as well as objects' recognition. Parents stated that their child performed better in the environment. They had less accidents with objects and individuals. They were more comfortable in walking and using stairs.

Conclusion: using tablets and smart phones by visually impaired children can improve distant vision and increase their functionality in performing daily life activities.

Keywords: Visually impaired children, Tablet, Smart phone, Visual acuity. 


\section{Introduction}

The common causes of vision impairment among children in industrialized countries include disorders in visual pathways, retina, optic nerve disorders and glaucoma (Kong, Fry, Al-Samarraie, Gilbert, \& Steinkuller, 2012; Rahi, Cable, \& Group, 2003). Some studies in Iran indicate that the common causes of vision impairment among children are optic nerve atrophy, congenital cataracts, corneal opacities, congenital glaucoma and albinism. Also genetic disorders play an important role in vision impairment among children in Iran (Ostadi-Moghaddam, Khabbaz-Khoub, Yekta, Heravian, \& Mehdi-Zadeh, 2007)

Vision impairment has affected nearly three million children worldwide (C. Gilbert \& Muhit, 2008; C. E. Gilbert \& Ellwein, 2008). Reduction in vision has a negative impact on the quality of life which leads to depression, increased risk of falling, lack of independence, educational problems as well as employment problems in the future (Brody, et al., 2001; Horowitz, Reinhardt, Boerner, \& Travis, 2003).

Rehabilitation services such as optical and non-optical aids as well as assistive technologies can help visually impaired children to improve their performance in their daily activities (Vingolo, De Rosa, Domanico, \& Anselmucci, 2015). Increasing light and contrast, making objects larger, talking tools, large font books, absorptive filters and electronic magnifiers are helpful ways to improve vision function.

Recent efforts have been made to develop new visual aids such as digital technologies, various software applications, screen readers and digital audio devices (Crossland, et al., 2017; Irvine, et al., 2014; Walker, Bryan, Harvey, Riazi, \& Anderson, 2016). Furthermore, changing color and contrast, using inverted contrast, different fonts and line spacing magnification have greater efficiency in their daily life (Gill, Mao, Powell, \& Sheidow, 2013) .These new technologies have improved the quality of life.However, there are very a few studies on the impact of these new technologies (Crossland, et al., 2017).

Treatment based video games for functional vision in children with hemianopia and brain damage showed that games (adapted to needs of children with cortical blindness) can improve functional vision (Linehan, Waddington, Hodgson, Hicks, \& Banks, 2014). Also, playing computer games improves movement and concentration in children with visual impairment (Nyquist, Lappin, Zhang, \& Tadin, 2016). Visual training with computer in visually impaired people could increase the visual field. Therefore by stimulating these areas, the size of the visual field can be increased (Sabel \& Kasten, 2000). New digital devices may play a significant role in improving vision function, quality of life, more independence and self-esteem in children with visual impairment. The aim of this study was to evaluate the impact of using tablets on vision in a group of visually impaired children.

\section{Materials and Methods}

Participants were selected from the Low Vision Center of Iran University of Medical Sciences and Low Vision Clinic of Baqiyatallah Hospital. The purpose of the study was explained to the parents of the children. Far and near visual acuity with LogMar chart were measured. Refraction was measured using autorefractometer. Participants were cooperative for this test. Other examinations were slit lamp examination and ophtalmoscopy.

To assess functionality in near vision, children were asked to paint images from a painting book and time was recorded. This test was repeated at the end of the study to evaluate the functionality in performance task at near vision.

A questionnaire was designed to assess the quality of the life of children. This questionnaire had 25 questions which evaluated children's functionality, such as painting, playing computer games, playing balls, face recognition, identifying family members, vision in different lighting, watching television, and communicating with other people. The validity and reliability of this questionnaire was approved by the statistical center of Mashhad University of Medical Sciences (Cronbach's alpha, 74\%). Parents were asked to answer the questions.

Children were also divided into two groups. The tablet group included children who had to work with a 
tablet at least 2 hours a day for about 6 months. The control group included children who did not use a tablet during this period. The tablet group was contacted once a week to check their status of using the tablet per day. Re-examination was performed after 6 months for both groups. A very short interview was conducted with the parents at the end of study in order to express any behavioral changes in their children. These comments were recorded for further evaluation.

After examining the normal or normal stretching or skewness of the data distribution, the Shapiro-Wilk test or the Kolmogorov-Smirnov test was used to ensure that the data is normal. Then Statistic analysis was done using T- test, Mann- Whitney and wilcoxon test.

The research was approved at the Regional Ethics Committee of Mashhad University of Medical Sciences (Ethics Code: IR.MUMS.REC.1395.16).Results

109 participants were invited for the study but, only 24 children between 4 and 13 years old (mean age $=8$ years) participated in this study. 9 children were girls and 15 were boys. The range of far vision to light perception was between 20/80 (0.6 Log Mar). Near vision varied from 20/30 (0.2 Log Mar) to 20/2000 (2.0 Log Mar).

The mean far visual acuity of the tablet and the control group before conducting the study were 1.6 \pm 0.68 and $1.27 \pm 0.48$ respectively. There were no significant differences $(P=0.17)$.

The mean near visual acuity of the tablet and the control group before conducting the study were 1.00 $\pm 0.7373 / 0$ and $1.04 \pm 0.32$ respectively. There were no significant differences $(P=0.95)$

The mean far visual acuity of the tablet and the control group after the study were $1.45 \pm 0.63$ and 1.32 \pm 0.46 respectively. There were no significant differences $(P=0.6)$.

The mean near visual acuity of the tablet and the control group after the study were $1.02 \pm 0.7$ and 1.04 \pm 0.32 respectively. There were no significant differences $(P=0.95)$

The equivalent refractive errors were between -12 $\mathrm{D}$ to $+7 \mathrm{D}$.

Table 1. shows the main cause of vision impairment among participants.

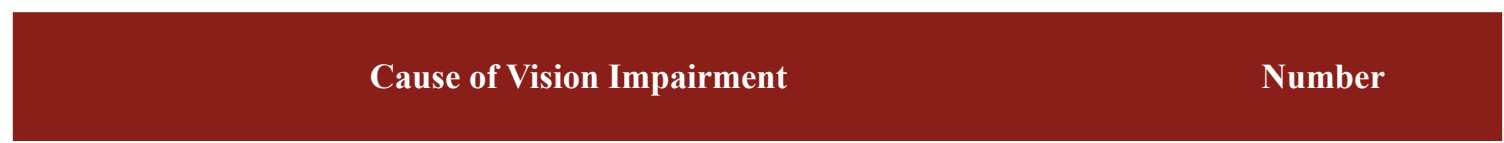

Corneal opacity

Congenital glaucoma

Central nervous system damage

Lebers congenital Amaurosis (LCA)

Retinitis pigmentosa (RP)

Optic nerve defects

Pathologic myopia
1

3

3

3

Retinal problems such as cone and rod dystrophy, retinopathy of prematurity and coloboma 
13 children $(54.2 \%)$ were in the tablet group and 11 $(45.8 \%)$ were in the control group.

Distant vision was compared before and after intervention in both groups. There was no significant difference in the distance vision between the two groups before using a tablet. However, after using a tablet, there was $0.20 \log$ Mar better vision in the tablet group in compare with the control group $(P=$ 0.04). 11 children from the tablet group had slight changes in their distant vision. However; two children had no significant changes. In the control group, eight people had no changes in distant vision, and three people had reduced distant vision.

In regards to near vision, there was no significant difference between the tablet and the control group before and after intervention. However, in the tablet group, two children had slight increase in their near vision, one child had decreased vision and four children had no changes.

There was no significant difference between refractive errors of children in the two groups before and after intervention $(P=0.07)$. The results showed that the use of tablet did not have a statistically significant effect on the increase or decrease of refractive errors in visually impaired children.

Results from the painting task showed that there is no significant difference between both groups before and after intervention ( $P=0.34)$. However, a decrease in painting time was significant in both groups.

Table 2 shows the results from the questionnaire scores. There were no significant differences with regards to the scores of the questionnaire before intervention between the two groups. However, there was a significant difference between the two groups after intervention $(P=0.009)$. The average score in the tablet group was 14.04 units more than the control group, indicating an improvement in the functionality of children in their daily life.

Parent observations were also studied during this research. Table 3 indicates changes in children behaviors in the tablet group which is reported by parents. Unfortunately parents of the control group have not seen any significant changes during this period.

Table 2. Results from Questionnaire before and after intervention

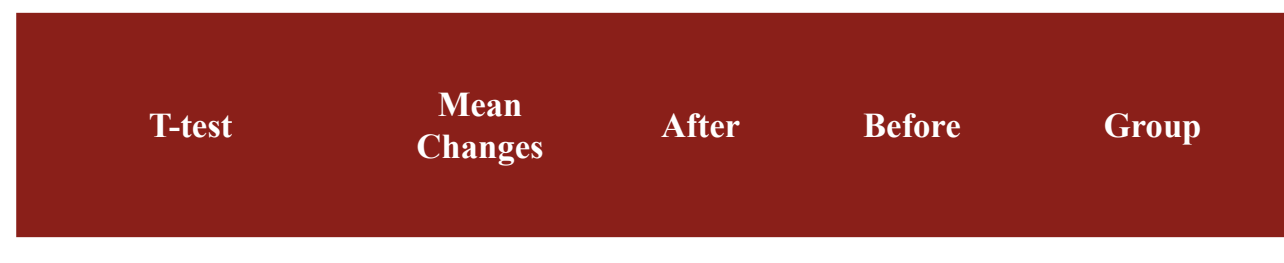

$\mathrm{t}=2.68$

$P=0.02$

$11.00 \pm 14.79 \quad 78.46 \pm 17.94 \quad 67.46 \pm 21.04$

Tablet

\begin{tabular}{ccccc}
$\mathrm{t}=-1.37$ & $5.45 \pm 13.20$ & $68.54 \pm 17.04$ & $74.00 \pm 19.67$ & Control \\
$\mathrm{t}=2.85$ & $\mathrm{t}=1.38$ & $\mathrm{t}=-0.78$ & \\
$P=0.009$ & $P=0.18$ & $P=0.44$ & T-test \\
\hline
\end{tabular}


Table 3. Parents' reports with regards to changes in their children's behaviors after using the tablet.

\begin{tabular}{|c|c|}
\hline Distant Vision & $\begin{array}{c}\text { watching } T V \text {, he used to sit very close to the TV, but now he is watching from a farther" } \\
\text { better in detecting tableware objects and gets less help. He used to ask too distance. He is } \\
\text { much, but now he calls objects' names and many things alone." }\end{array}$ \\
\hline Near Vision & $\begin{array}{l}\text { "His handwriting was larger and more irregular, but now it's smaller, more regular and } \\
\text { better. He's much more interested in smartphone and tablet. He sees details of photos and } \\
\text { names their very small components carefully. He could not detect labels behind clothes and } \\
\text { on the front and back of clothes, but now he is able to detect them without touching. }\end{array}$ \\
\hline Functionality & $\begin{array}{l}\text { "He becomes smarter and more cheerful. He has more competition in games. He is happier } \\
\text { and motivated. He has become more independent and active outside. His light detection } \\
\text { has become stronger now he does not like to close his eyes at all". "His mistakes in playing } \\
\text { computer games and reading have become less." }\end{array}$ \\
\hline Painting & $\begin{array}{c}\text { "My child makes his paintings more accurate and detailed". "Attention and concentration in } \\
\text { reading and painting have increased". "My child is more interested to paint and engage more } \\
\text { in painting." }\end{array}$ \\
\hline
\end{tabular}

\section{Discussion}

Many studies have been carried out on the effects of digital technology (such as tablets and smart phones) on the quality of life and vision. (Patodia, Golesic, Mao, \& Hutnik, 2017; Usumoto, Arai, Fujita, Cheng, \& Hirose, 2002). This study showed that working with a tablet can also improve vision. Also, this training increased distant vision by improving functionality of these children in their performance of daily activities such as improvement in orientation and mobility, as well as detecting objects and obstacles. This improvement was obvious for the parents. Parents reported clear reactions to objects in environment, better detection of colors and less accidents of hitting objects and people. Children also have become more comfortable in walking and using stairs, according to their parent's observation. They have also adapted to more natural behaviors and movements. Children who used a tablet were more interested to go outside and do things. Based on parents talk, it seems that children with severe low vision in the tablet group be- came more sensitive to slight changes in light as well as showed quick responses.

Although no significant change was found in near vision, but vision functionality improved. It may be due to changes in other parameters of visual function; such as contrast, eye movements, greater stability in fixation and an increase in the size of the visual field. Also, parents reported better performance in near task in the tablet group; such as paying attention to details in writing and painting, better detection of details and more interest in watching TV. Parents also stated that the use of touch in tablet groups has become less. There is also an interest in internet and more research. They also spend more time surfing the web.

In terms of painting, children showed a significant increase in speed, and painting time was reduced to $50 \%$. Children obtain more skills in painting over the past six months. It seems that tablets and smartphones have had a positive impact on their vision, as parents observed more motivation in painting with detail. 
"My child paints more accurately and in a detailed manner"

High scores from the results of the questionnaire in the tablet group also show that work with tablet improves not only skills but also the quality of life. Children also become more independent.

Parents expressed significant changes in the performance of their children. It seems that these positive changes in behaviors may be due to flexibility in the brain of the case group. It is believed that neurons damages is a permanent injury and no improvement can occur (Willey \& Mayer, 2011). However, recently, scientists believe that brain organization continues by forming new connections throughout human life(Woolpert \& Reilly, 2016). This phenomenon is called neuroplasticity. Therefore, working with tablets and smartphones may stimulate remaining cells and nerve fibers. In a study about the treatment based video game for functional vision in children with hemianopia and brain damage, it was concluded that the game (adapted to needs of children with cortical blindness) can improve functional vision (Linehan, Waddington, Hodgson, Hicks, \& Banks, 2014). In another study in 2016, it was stated that playing computer games improves movement and concentration in children with visual impairment (Nyquist, Lappin, Zhang, \& Tadin, 2016). Also, Ballestone et al. in 2014 found that brain training with non-action video games increases perception and recognition in adults.

Another study also found that 6 months visual train-

\section{References}

Brody, B. L., Gamst, A. C., Williams, R. A., Smith, A. R., Lau, P. W., Dolnak, D., et al. (2001). Depression, visual acuity, comorbidity, and disability associated with age-related macular degeneration. Ophthalmology, 108(10), 1893-1900.

Crossland, M. D., Thomas, R., Unwin, H., Bharani, S., Gothwal, V. K., Quartilho, A., et al. (2017). Tablet computers versus optical aids to support education and learning in children and young people with low vision: protocol for a pilot randomised controlled trial, CREATE (Children Reading with Electronic Assistance To Educate). BMJ open, 7(6), ing with computer in visually impaired people could increase the visual field. It is assumed that some places in the brain may not be completely damaged, and the system is relatively disturbed. Therefore, by stimulating these areas, the size of the visual field can be increased (Sabel \& Kasten, 2000). Results of these studies also confirm that new digital devices can play a significant role in improving vision function, quality of life, and provide more independence and selfesteem in children with visual impairment.

\section{Conclusion}

using tablets and smart phones by visually impaired children can improve distant vision and increase their functionality in performing daily life activities. Therefore, it may have an important role in improving the quality of life for this group of visually impaired people.

\section{Acknowledgment}

All authors thank those who helped them writing this article. The present article is derived from a Msc. thesis (belonging to the first author), code number 951426. This study was funded by the Paramedical School of Mashhad University of Medical Sciences and all benefits of this project are related to this University center.

\section{Conflict of Interest Statement}

The authors declare no conflict of interest.

\section{e015939.}

Gilbert, C. E., \& Ellwein, L. B. (2008). Prevalence and causes of functional low vision in school-age children: results from standardized population surveys in Asia, Africa, and Latin America. Investigative ophthalmology \& visual science, 49(3), 877881.

Gilbert, C., \& Muhit, M. (2008). Twenty years of childhood blindness: what have we learnt? Community Eye Health, 21(67), 46.

Gill, K., Mao, A., Powell, A., \& Sheidow, T. (2013). Digital reader vs print media: the role of digital technology in reading accuracy in age-relat- 
ed macular degeneration. Eye, 27(5), 639.

Horowitz, A., Reinhardt, J., Boerner, K., \& Travis, L. (2003). The influence of health, social support quality and rehabilitation on depression among disabled elders. Aging \& mental health, 7(5), 342-350.

Irvine, D., Zemke, A., Pusateri, G., Gerlach, L., Chun, R., \& Jay, W. M. (2014). Tablet and smartphone accessibility features in the low vision rehabilitation. Neuro-Ophthalmology, 38(2), 53-59.

Kong, L., Fry, M., Al-Samarraie, M., Gilbert, C., \& Steinkuller, P. G. (2012). An update on progress and the changing epidemiology of causes of childhood blindness worldwide. Journal of American Association for Pediatric Ophthalmology and Strabismus, 16(6), 501-507.

Linehan, C., Waddington, J., Hodgson, T. L., Hicks, K., \& Banks, R. (2014). Designing games for the rehabilitation of functional vision for children with cerebral visual impairment. Paper presented at the Proceedings of the extended abstracts of the 32nd annual ACM conference on Human factors in computing systems.

Nyquist, J. B., Lappin, J. S., Zhang, R., \& Tadin, D. (2016). Perceptual training yields rapid improvements in visually impaired youth. Scientific reports, 6,37431 .

Ostadi-Moghaddam, H., Khabbaz-Khoub, M., Yekta, A., Heravian, J., \& Mehdi-Zadeh, A. R. (2007). An Investigation in Causes of Severe Visual Impairment and Blindness of the Students from the Blind Schools of Mashad. Journal of Rehabilitation, $8(1)$.

Patodia, Y., Golesic, E., Mao, A., \& Hutnik, C. M.
(2017). Clinical effectiveness of currently available low-vision devices in glaucoma patients with moderate-to-severe vision loss. Clinical Ophthalmology (Auckland, NZ), 11, 683.

Rahi, J. S., Cable, N., \& Group, B. C. V. I. S. (2003). Severe visual impairment and blindness in children in the UK. The Lancet, 362(9393), 13591365.

Sabel, B. A., \& Kasten, E. (2000). Restoration of vision by training of residual functions. Current opinion in ophthalmology, 11(6), 430-436.

Usumoto, N., Arai, M., Fujita, K., Cheng, H., \& Hirose, T. (2002). An Efficacy and Eligibility Study of Portable Closed-Circuit Television as a LowVision Aid. Investigative Ophthalmology \& Visual Science, 43(13), 3831-3831.

Vingolo, E. M., De Rosa, V., Domanico, D., \& Anselmucci, F. (2015). Low vision rehabilitation: Current perspectives. Clinical Optometry 7, 53-58.

Walker, R., Bryan, L., Harvey, H., Riazi, A., \& Anderson, S. J. (2016). The value of Tablets as reading aids for individuals with central visual field loss: an evaluation of eccentric reading with static and scrolling text. Ophthalmic and Physiological Optics, 36(4), 459-464.

Willey, J. Z., \& Mayer, S. A. (2011). Brain injury clinical trials: new agents or new statistics?. Critical Care, 15(5), 188.

Woolpert, D., \& Reilly, J. S. (2016). Investigating the extent of neuroplasticity: Writing in children with perinatal stroke. Neuropsychologia, 89, 105118. 


$$
\text { مقاله يزوهشى }
$$

\section{بررسى تأثير كاربرد تبلت و كوشىهاى هوشمند بر حدت و عملكرد بينايى كودكان كمبينا

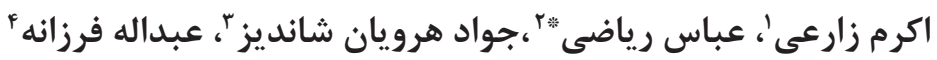
ا. ا. كارشناسى ارشد إيتومترى، كروه آموزشى إيتومترى، دانشكدة علوم بيرايزشكى، دانشكاه علوم يز شكى مشهد، مشهد، ايران

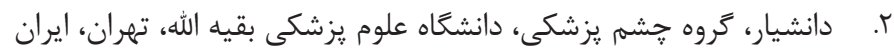

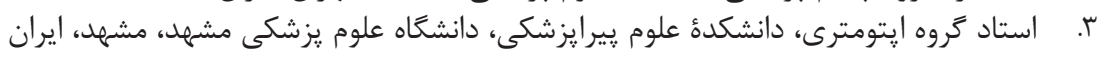

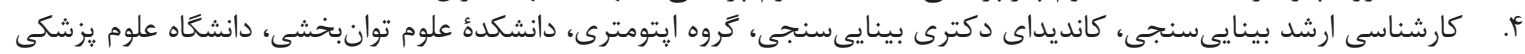

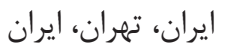



